\title{
Management Reviewing Literature: An Evaluation of Selected Characteristics
}

\author{
Sajjad ur Rehman
}

Selected characteristics of the reviewing literature of management are described. These include lag time, review length, the descriptive or analytical nature of the review, positive or negative evaluation, and the affiliation of the reviewer. The various treatments given to these characteristics by the reviewing media are compared. Trade journal reviews are brief, relatively current, and descriptive. Opinions are mostly favorable or neutral. Professional journal reviews are less current, give a detailed and critical treatment, and are evaluative. Signed reviews tend to be more analytical than unsigned reviews. The length of the review is significantly related to treatment and evaluation.

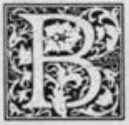

ook reviews serve a variety of purposes. They are an established means of informing a potential market of the appearance of new publications. The awareness function of the reviewing media is helpful to the general readership as well as to professional book selectors of libraries in their selection decisions. Another important function of reviews is to provide an intellectual forum of peer appraisal for a new publication to assess its contribution to the body of knowledge in a particular field. Recognition is accorded to a new book and its authors through this means. It is also an accepted norm of the fabric of professional life to examine the content of a new book and the expressed ideas and opinions of its author by subjecting it to a rigorous scrutiny in the book review column of a journal. Further, the very fact that a book is reviewed brings wider recognition and prestige to a monograph and its author.

Book reviews are an important selection tool in libraries. The greater the pressure for efficient use of funds, the more hard pressed a selector feels to make effective selection decisions, which in turn often rely heavily on the reviewing media. Many large libraries may be engaged in mass buying programs, but in most small and medium-sized libraries, librarians continue to select title by title. Even the large libraries often check the effectiveness of their mass buying and approval plans by noting reviews as they appear.

The number of periodicals in any discipline that contain book reviews is so large that it becomes a virtually impossible task to see them all. The reviewing journals also vary considerably in their coveragein specific books selected, in length, in treatment (descriptive or critical), in lag time, in type of reviewer. A systematic examination of these attributes is the only way of identifying the most useful reviewing sources. A review of related literature indicates very few studies that examined

Sajjad ur Rehman is at King Fahd University of Petroleum \& Minerals Library, Box 1919, in Dhahran 31261, Saudi Arabia. The author acknowledges with deep appreciation the contribution of Marcy Murphy, Associate Professor, School of Library and Information Science, Bloomington, Indiana, toward extensive review and editing of the earlier draft. 
some of the variables in reviewing journals. Some book reviews studies examined selected variables of trade reviewing journals. ${ }^{14}$ These studies, however, have little usefulness for those interested in the book reviews of a specialized field or discipline. One pioneering research project in a specialized field was conducted by Ching-Chih Chen, who examined book reviewing in the professional journals of biomedical sciences. It was a comprehensive study and covered many significant variables of the biomedical book reviewing media..$^{5-8}$ Because this study is confined to the reviewing literature of a specialized field, the trade reviewing journals are automatically excluded, as they do not cover books published in specialized fields of theoretical or applied sciences.

The reviewing literature of library and information science was studied by Chen and Thomas Galvin.' Although the reviews of biomedical and librarianship literatures have different characteristics, several bibliometric similarities emerge from the two studies. For example, a high yield core of journals was isolated in both fields, wherein a small percentage of journals covered a large percentage of reviews. It was also confirmed that a few books were reviewed repeatedly; however, the majority of the books published in a field was reviewed minimally or not at all.

Additional attributes examined in the studies of Chen, Chen and Galvin, and others included lag time between the date of publication and review date, review length, the descriptive or critical nature of the reviews, the number of positive or negative evaluations of the reviewed monographs, and affiliations of the reviewers. Questions about the selection policies of reviewing journals, operational criteria, and methodology for soliciting reviews, and other related variables have been addressed by other studies. ${ }^{10-12}$

Management reviewing media have not been subjected thus far to any systematic examination for the identification of a core of high-yield journals that should be both priority purchases for libraries and necessary reading for practitioners and researchers. An examination of the perti- nent variables of the management reviewing journals is considered crucial for identifying the most effective reviewing journals in the field. Ulrich's twentyfourth edition lists 509 titles under the heading of "Management," and the sheer volume of journal publications makes it important to identify a selected core based on the criteria of most pertinent variables.

Reviewing studies cited earlier do not make any distinction between the professional or scholarly journals of a discipline and book trade journals. Book trade journals do not contain reviews of monographs in the domain of pure or applied sciences. However, the monographic literature in the fields of humanities and social sciences is commonly reviewed by both professional and book trade journals.

A comparative study of the treatment of book reviews in these two types is considered of paramount interest for both the consumers of reviews and the monograph publishers.

Professional journals are defined as both those that clearly belong to the field of business management and also those that are from related academic disciplines. Book trade journals are defined as those that are commonly recognized as belonging to book trade or the field of library and information science. Those journals that do not belong to the book trade category are treated as belonging to the other category.

\section{OBJECTIVES OF THE STUDY}

The results of the first-part of this study of management reviewing literature are related to the identification of a core of high-yield journals and the degree of overlap among the reviewing journals. These results have been published elsewhere. ${ }^{13}$ The chief purpose of this paper is to investigate the following characteristics or attributes of the reviewing literature of management: lag time (the time that elapses between the publication date of a book and the appearance of a review), the length of the reviews, whether the reviews are descriptive or analytical, the kind of evaluation given in the reviews (favorable, neutral, or unfavorable), whether they are signed or unsigned, and the affili- 
ation of the reviewers. The same variables have been used by the earlier reviewing studies and constitute the fundamental criteria for measuring the effectiveness of reviews.

It is also of considerable interest to test for statistically significant relationships of the variables of review length, signed or unsigned status, and the affiliation of reviewers with the kind of treatment they receive (descriptive or analytical) and their evaluative slant (favorable, neutral, or unfavorable). These relationships have not been investigated by the earlier studies of reviewing journals. Three specific research questions are investigated in this study: (1) Is the review length significantly related to the evaluation of a review (favorable, neutral, or unfavorable)? (2) Is the review status (signed or unsigned) significantly related to its descriptive or analytical nature and its evaluative slant? (3) Is the reviewer affiliation significantly related to its descriptive or analytical nature and its evaluative slant?

A peripheral objective of the study is to compare and contrast the reviews in two types of reviewing journals on the basis of lag time, length, descriptive or analytical nature, and evaluative slant.

\section{METHODOLOGY}

Monographs published in 1981 and listed in the 658 classification of American Book Publishing Record $(A B P R)^{14}$ were selected for the sample. The publication date of 1981 was chosen because it seemed likely that the three-year period, 1981-84, would be sufficient time for the majority of the reviews to have appeared and to have been included in major indexing services of book reviews.

After locating 604 titles in $A B P R$, these were checked, first, through the separate book review sections of Business Periodicals Index ${ }^{15}$ for 1980-81 through 1983-84 (the year 1980 was included to catch any prepublication reviews). The same titles were then checked in the 1980-83 volume of Book Review Index. ${ }^{16}$ It was assumed that $B P I$ and $B R I$ would adequately cover the management reviewing media in both the professional journals of management and the general trade reviewing media. Of the total sample (604), 575 citations were located in 117 journals for reviews of 252 books.

All but 11 reviews were obtained, resulting in a final collection of 564 reviews from 114 journals, or $98.1 \%$ of the total (575) reviews; 18 of the 114 journals plainly belonged to the category of book trade or the field of library and information science.

The reviews were analyzed and coded for several variables, including title and date of the book, approximate number of words, descriptive or analytical nature, evaluative slant, and name and affiliation (when given) of the reviewer. Chi-square was used to test the significance of results by using proportions of the data for different categories. ANOVA was performed to test the significance of results for noncategorical data.

\section{FINDINGS}

The sample consisted of 564 book reviews, at least one each for 252 , or $41.7 \%$, of the 604 monographs listed in $A B P R$ for 1981. However, no reviews were found for 352 books, or $58.2 \%$ of the original 604 .

A core of 19 reviewing journals, or $16.6 \%$ of the 114 , was identified. Each journal carried at least eight reviews of the books in the sample. Table 1 displays data for these journals, ranked according to their rate of productivity. Together, these 19 journals contained 363 , or $64.4 \%$, of the total 564 reviews. Also included in the table for each journal is the average reviewing lag time, the number of descriptive or critical reviews, and the number that were favorable, neutral, or unfavorable.

\section{Lag Time}

The prompt appearance of reviews is important for alerting librarians and potential readers to new publications, and accordingly, the value of reviews diminishes with time. This has been particularly true in recent decades, because publishers have issued shorter runs, with the result that books go out of print more quickly.

A book's precise date of publication was taken from the book review, or if not available, from Bowker's announcement media. Month of publication for 83 reviewed titles could not be ascertained and were 
excluded from this portion of study. The number of reviews for these 83 titles was 195, which left 349 usable reviews.

The mean lag time for all 349 reviews in the sample was 7.5 months. There was a wide range, from less than 11 months (prepublication announcements) to 32 months after date of publication. Books are often reviewed before they are published if galley proofs or unfinished copies are supplied to journal editors.

Interestingly, this time lag of 7.5 months for management titles was only slightly less than the 8-month average lag in reviewing that Chen found for biomedical books. This suggests that the discipline may not affect the time it takes a review to appear.

The 7 journals that usually carried reviews within 4 months of publication date were Kirkus (.3 months); Personnel Management (.5 months); Publishers' Weekly (1.7 months); Library Journal (2.1 months); Choice (3.8 months); Booklist (4.3 months); and British Book News (4.4 months).

Lag time for most of the trade journals in this core sample was considerably less than for the professional journals, indicating that trade journals generally do a better job of alerting. An exception was Personnel Management.

\section{Descriptive and Analytical Reviews}

A descriptive review was defined as one that briefly mentions the author's purpose, the book's scope and format, some general information about its contents, and sometimes a brief physical description in addition to providing the bibliographical information. There is little or no attempt at critical evaluation, or analysis, and the review is usually quite brief. Analytical or critical reviews, on the other hand, evaluate the content of the book in the context of the body of literature available and often suggest the type of readers to whom the book will chiefly appeal. It was anticipated that the professional journals' treatment of reviews would be different from that of general periodicals. ${ }^{18}$

Of the total 564 reviews, 225 , or $39.9 \%$, were descriptive and 339 , or $60.1 \%$, analytical. The trade journals had far more descriptive reviews than the professional journals. For example, 54 of the 59 reviews in Library Journal were descriptive. But in Personnel Psychology, 54 of the 56 reviews were analytical. Running true to form, Choice, Booklist, Publishers Weekly (PW), and Kirkus carried a higher percentage of descriptive reviews, $70.5 \%, 84.4 \%, 83.3 \%$, and $68.8 \%$, respectively. Booklist, of course, usually does not carry a review unless the book is recommended, and $P W$ is primarily an announcement medium. Data on percentage of descriptive or analytical reviews for each of the 19 journal titles can be found in table 1 .

\section{Length of Reviews}

The average length of the 564 reviews was 575 words. There was a wide range: some journals published reviews of 100-200 words, while others had extensive reviews running to several hundred or even more than 1,000 words. For example, the average length of a review in $\mathrm{Li}$ brary Journal was 106 words; in Personnel Psychology, 1,354. The average lengths of reviews in Kirkus, Choice, Booklist, and British Book News were found to be 286, $150,133,113$, and 296 words, respectively. All 6 trade journals had shorter reviews than any of the management journals.

It seems reasonable to assume that brief but very current reviews are more useful for acquisition efforts, and that the lengthier reviews of professional journals inform scholars and professional managers in a more leisurely manner of the contribution of an author to the body of knowledge in their field. Timeliness is not as important in such a case.

\section{Evaluative Slant of Reviews}

Other studies of reviewing literature have shown that more reviews are favorable, some are neutral, and very few are negative. Covey reported that $90 \%$ of 1,777 reviews of 1,032 reference books that appeared between 1966-70 were either favorable or mixed. ${ }^{19}$ The study of the reviewing literature of librarianship showed that $70.9 \%$ of the reviews were favorable and $10 \%$ were without any definite opinion. $^{20}$

The results of this study resemble the results of these earlier studies quite 
TABLE 1

CHARACTERISTICS OF THE CORE REVIEWING MEDIA

\begin{tabular}{|c|c|c|c|c|c|c|c|c|}
\hline Title & $\begin{array}{l}\text { Number } \\
\text { of } \\
\text { Reviews }\end{array}$ & $\begin{array}{l}\text { Review } \\
\text { Length } \\
\text { Words, } \\
\text { Mean }\end{array}$ & $\begin{array}{l}\text { Time Lag } \\
\text { Months, } \\
\text { Mean }\end{array}$ & $\begin{array}{l}\text { Nature of } \\
\text { Descriptive }\end{array}$ & & & & Favorable \\
\hline Library Journal & 59 & 106 & 2.1 & \multirow{19}{*}{$\begin{array}{r}54 \\
(91.5 \%) \\
2 \\
(3.6 \%) \\
31 \\
(70.5 \%) \\
27 \\
(84.4 \%) \\
15 \\
(83.3 \%) \\
11 \\
(68.8 \%) \\
1 \\
(7.1 \%) \\
9 \\
(64.3 \%) \\
X \\
X \\
X \\
\\
1 \\
(9.1 \%) \\
2 \\
(20 \%) \\
3 \\
(30 \%) \\
1 \\
(11.1 \%) \\
2 \\
(22.2 \%) \\
X \\
5 \\
(62.5 \%) \\
X \\
\end{array}$} & \multirow{19}{*}{$\begin{array}{r}5 \\
(8.5 \%) \\
54 \\
(96.4 \%) \\
13 \\
(29.5 \%) \\
5 \\
(15.6 \%) \\
3 \\
(16.7 \%) \\
5 \\
(32.2 \%) \\
13 \\
(92.9 \%) \\
5 \\
(35.7 \%) \\
14 \\
(100 \%) \\
11 \\
(100 \%) \\
11 \\
(100 \%) \\
10 \\
(90.9 \%) \\
8 \\
(80 \%) \\
7 \\
(70 \%) \\
8 \\
(88.9 \%) \\
7 \\
(77.8 \%) \\
9 \\
(100 \%) \\
3 \\
(37.5 \%) \\
8 \\
(100 \%) \\
\end{array}$} & \multirow{19}{*}{$\begin{array}{r}\text { Unfavorable } \\
5 \\
(8.5 \%) \\
8 \\
(14.3 \%) \\
X \\
X \\
X \\
1 \\
(5.6 \%) \\
1 \\
(6.3 \%) \\
1 \\
(7.1 \%) \\
1 \\
(7.1 \%) \\
X \\
2 \\
2 \\
(18.2 \%) \\
2 \\
(18.2 \%) \\
X \\
3 \\
3 \\
(30 \%) \\
1 \\
(10 \%) \\
X \\
X \\
X \\
X \\
1 \\
(12.5 \%) \\
1 \\
(12.5 \%) \\
\end{array}$} & \multirow{19}{*}{\multicolumn{2}{|c|}{ 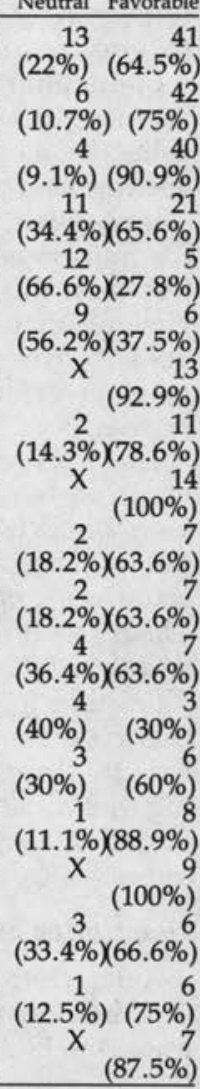 }} \\
\hline Personnel Psychology & 56 & 1,354 & 7.8 & & & & & \\
\hline Choice & 44 & 150 & 3.8 & & & & & \\
\hline 3ooklist & 32 & 113 & 4.3 & & & & & \\
\hline ublishers Weekly & 18 & 133 & 1.7 & & & & & \\
\hline irkus Reviews & 16 & 286 & 3 & & & & & \\
\hline ccounting Review & 14 & 603 & 8.6 & & & & & \\
\hline arvard Business Review & 14 & 309 & 11.9 & & & & & \\
\hline reannel Admir & 14 & 571 & 6.9 & & & & & \\
\hline cademic Management Review & 11 & 1,261 & 11.5 & & & & & \\
\hline 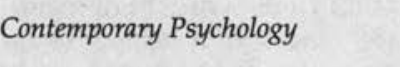 & 11 & 1,064 & 11.7 & & & & & \\
\hline erconnel Manocoment & 11 & & .5 & & & & & \\
\hline urnal of Management Studies & 10 & 803 & 10.3 & & & & & \\
\hline 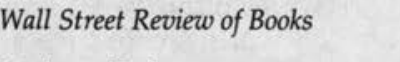 & 10 & 1,027 & 7.2 & & & & & \\
\hline usiness Horizons & 9 & 1,179 & 13.0 & & & & & \\
\hline dustrial Marketing Management & 9 & 569 & 9.6 & & & & & \\
\hline Herations Kesearch & 9 & 482 & 12.7 & & & & & \\
\hline ritish Book News & 8 & & 4.4 & & & & & \\
\hline The Banker's Magazine & 8 & 609 & 8.1 & & & & & \\
\hline
\end{tabular}

closely. More than $91 \%$ of the reviews were either favorable or neutral, and only $8.3 \%$, or 47 of 564 reviews, were negative. More specifically, 365 , or $64.9 \%$, of the reviews were positive; 151 , or $26.8 \%$, were neutral. Most journals in the sample showed a similar individual evaluative distribution, the largest percentage consisting of favorable reviews, followed by neutral, then negative or unfavorable. For example, among the most productive journals, Library Journal and Personnel Psychology have 8.5 and $14.3 \%$ negative, 64.5 and $75 \%$ favorable, and 22 and $10.7 \%$ neutral reviews, respectively.

Such a high rate of favorable reviews has been questioned by many, including
Chen and Galvin, and they suggest that this "chorus of praise" is either due to the reviewing policies of journals or the absence of critical reviews in the field of librarianship. ${ }^{21}$ Other studies, however, indicate that this same phenomenon has been observed in the reviewing literature of many disciplines. One explanation may be that editors exercise a rigorous screening policy and accept for review only those books they judge to be very good. There are doubtless many other criteria, including interests of the readership and peer pressure from the professional community. McLeod reported that Library Journal selected only $25 \%$ of the titles received annually. ${ }^{22}$ The rationale that lies behind 
these decisions would be interesting to pursue in depth.

\section{Review Length and Evaluative Slant}

The other objective of the study was to see whether or not any significant relationships existed between review length and the kind of evaluation. The research question regarding the relationship of evaluative slant to review length was considered first for the statistical test. The mean scores for length of unfavorable, neutral, and favorable reviews were 1,053 , 487 , and 591 words, respectively.

The statistical test of analysis of variance (ANOVA) was performed to test the significance of these differences. The results of the test are given in figure 1 . The test reported an $F$ value of 13.82 for 563 degrees of freedom, which is significant at the criterion of .05. An additional test of Duncan Multiple Range was performed to ascertain the applicability of significant differences within groups among the three categories. Figure 1 also contains the results of this test, which suggest that the unfavorable reviews are significantly longer than favorable or neutral ones and that favorable reviews are significantly longer than neutral ones at the criterion of .05 .

\section{Reviewers and Their Affiliation}

Another objective of this study was to find out how many of the management reviews were signed and to determine the affiliations of the reviewers. It was interesting to see if either signed or unsigned reviews had distinguishing characteristics and also to note if there were relationships between affiliation of reviewers and reviews that were descriptive or analytical, on the one hand, or positive, neutral, or favorable, on the other.

Of the total 564 reviews, 373 (66\% were signed; 191 (34\%) unsigned. Table 2 includes the totals of signed and unsigned reviews and reviewer affiliations of the 19 reviewing journals. In Library Journal, 40 of the 59 reviews were signed; in Personnel Psychology, all were signed. The reviews in Accounting Review, Personnel Administrator, Academic Management Review, Contemporary Psychology, Journal of Management Studies, and the Banker's Magazine carried

Mean scores for review length

Neutral $\quad=487.4$

Favorable $\quad=591.2$

Unfavorable $=1053.1$

ANOVA TABLE

\begin{tabular}{|c|c|c|}
\hline Sum of Squares & Degrees of Freedom & Mean Square \\
\hline $.1159 \mathrm{E}+08$ & 2 & $.5795 \mathrm{E}+07$ \\
\hline $.2352 \mathrm{E}+09$ & 561 & $.4193 \mathrm{E}+06$ \\
\hline $.2468 \mathrm{E}+09$ & 563 & \\
\hline
\end{tabular}

Observed $\mathrm{F}=13.82>\mathrm{F}_{\cdot 05}=3.00$

DUNCAN MULTIPLE RANGE TEST

Standard error of treatment mean $=27.33$

$\begin{aligned} \text { Specified ranges at }{ }^{\alpha} .05^{*} \quad \mathrm{R}_{2} & =2.77 \times 27.33=75.7 \\ \mathrm{R}_{3} & =2.92 \times 27.33=79.8 \\ \text { Neutral versus Favorable } & =103.8>^{\alpha} .05=75.7 \\ \text { Neutral versus Unfavorable } & =565.7>^{\alpha} .05=79.8 \\ \text { Favorable versus Unfavorable } & =461.9>^{\alpha} .05=75.7\end{aligned}$

*Based on the Duncan Multiple Range Table in D. C. Montgomery, Design and Analysis of Experiments, $2 \mathrm{~d}$ ed. New York: Wiley, 1984. 


\section{TABLE 2}

REVIEWERS AND THEIR AFFILIATIONS IN THE CORE REVIEWING MEDIA

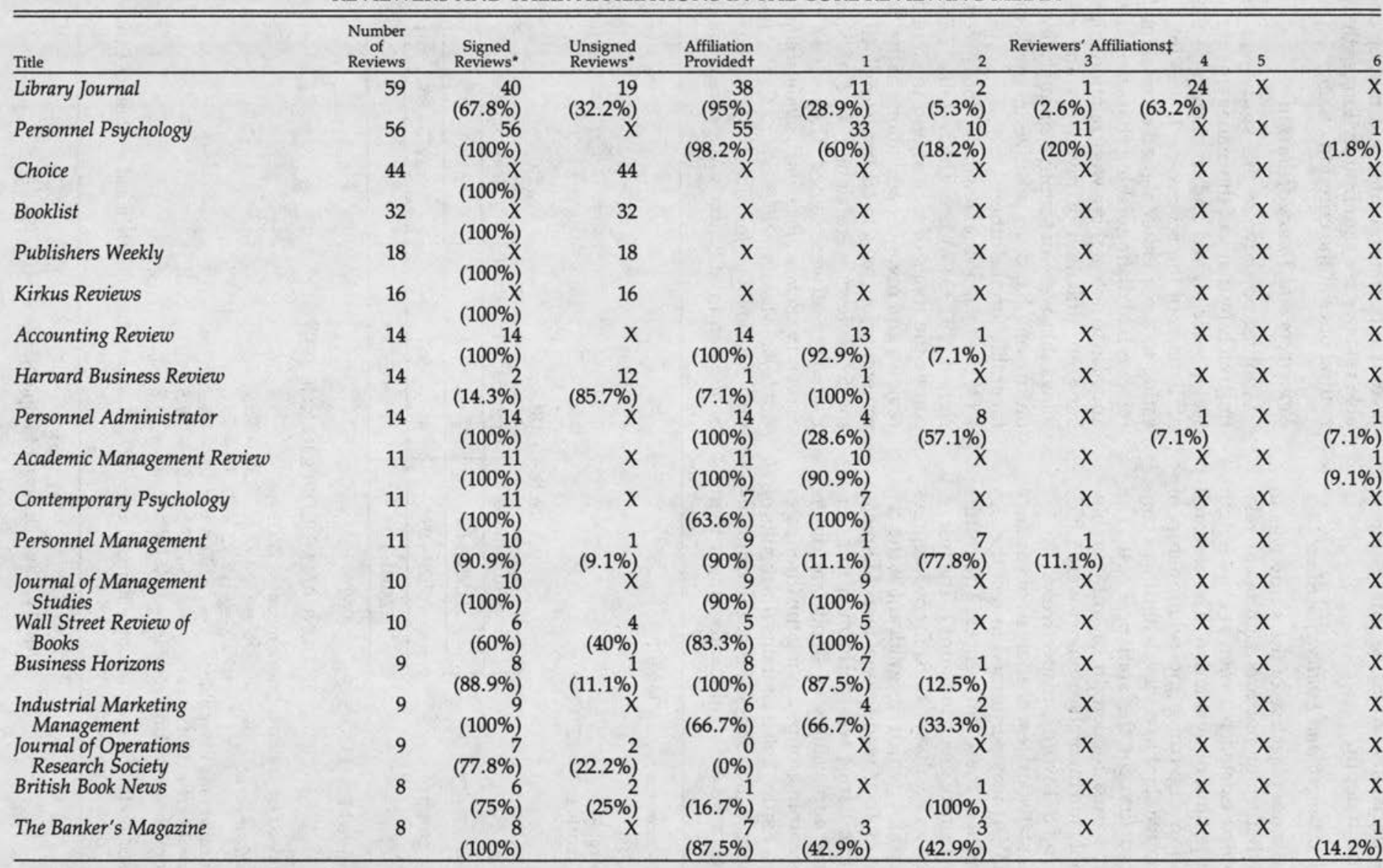

*Percentages of the total number of reviews in a journal

tPercentages of the total number of signed reviews.

$\ddagger$ Percentages of the total number of reviews for which affiliations were given. The descriptions of six categories of reviewer affiliations are 1-teaching faculty/officials of research centers in universities;

2-executives in organizations; 3-consultants/industrial psychologists; 4-librarians; 5-free-lance writers; and 6-affiliates of research agencies. 
signed reviews in most cases. Choice, Booklist, and Kirkus Reviews, on the other hand, had all the unsigned reviews. This is an interesting distinguishing characteristic between trade and professional management journals. Of the signed reviews, $293(78.8 \%)$ gave the affiliation of the reviewers.

This second group was then divided into six categories of affiliations: (1) teaching faculty, (2) corporate executives or staff members, (3) librarians, (4) consultants and industrial psychologists, (5) affiliates of research agencies, and (6) freelance writers. Table 3 lists these groups, and the numbers and percentages of reviews each produced. The largest group of reviewers consisted of $178(69.8 \%$ of the total) faculty members or research fellows in the universities. The next largest group, 56 , or $19 \%$, comprised executives or staff officers in corporations.

To investigate the second and third research questions, a proportional test of chi-square was suitable for the categorical data of this study. First, signed versus un- signed reviews were compared for their proportions of descriptive and analytical reviews. Figure 2 displays chi-square data used in this test. The criterion value of .05 was used for these tests. The raw chisquare value of the test was 160.9 with 1 degree of freedom, which was significant at .05 level, suggesting that the signed reviews were more likely to be analytical than the unsigned.

The same test was then performed to find out if there were significant relationships between evaluative slant and review status (signed and unsigned). Figure 3 shows the results of this test-raw chisquare value of 30.41 with 2 degrees of freedom, which is again significant at .05 level. This indicates that significantly fewer unsigned reviews were unfavorable. The proportion of neutral reviews was higher among unsigned reviews. The test also showed that in this case significantly more signed than unsigned reviews were favorable. This result implies that withholding a reviewer's identity may not be an effective strategy if the purpose is to

TABLE 3

REVIEWER AFFILIATIONS

\begin{tabular}{lcc}
\hline \hline Category of Affiliation & Frequency & Percentage \\
\hline Teaching faculty/affiliates of research & 178 & 60.8 \\
centers in universities & 56 & 19.1 \\
Executives/staff members in enterprises & 28 & 9.6 \\
Librarians & 20 & 6.8 \\
Consultants/industrial psychologists & 6 & 2.0 \\
Affiliates of research agencies & 5 & 1.7 \\
Free-lance writers &
\end{tabular}

\begin{tabular}{|c|c|c|c|}
\hline & DESCRIPTIVE & ANALYTICAL & ROW TOTALS \\
\hline Signed & $\begin{array}{r}79 \\
(21.2 \%)\end{array}$ & $\begin{array}{c}294 \\
(78.8 \%)\end{array}$ & $\begin{array}{c}373 \\
(66.1 \%)\end{array}$ \\
\hline Unsigned & $\begin{array}{c}146 \\
(76.4 \%)\end{array}$ & $\begin{array}{r}45 \\
(23.6 \%)\end{array}$ & $\begin{array}{c}191 \\
(33.9 \%)\end{array}$ \\
\hline \multirow[t]{2}{*}{ Column totals } & $\begin{array}{c}225 \\
(39.9 \%)\end{array}$ & $\begin{array}{c}339 \\
(60.1 \%)\end{array}$ & $\begin{array}{c}564 \\
(100 \%)\end{array}$ \\
\hline & \multicolumn{3}{|c|}{$\chi^{2}=160.0>{ }^{\alpha} .05 \times{ }^{\mathrm{df}} 1=3.84$} \\
\hline
\end{tabular}




\begin{tabular}{|l|c|c|c|c}
\hline \multicolumn{1}{c}{} & UNFAVORABLE & NEUTRAL & FAVORABLE & ROW TOTALS \\
\hline Signed & 43 & 77 & 253 & 373 \\
& $(11.6 \%)$ & $(20.6 \%)$ & $(67.8 \%)$ & $(66.1 \%)$ \\
\hline Unsigned & 4 & 74 & 113 & 191 \\
& $(2.1 \%)$ & $(38.7 \%)$ & $(59.2 \%)$ & $(33.9 \%)$ \\
Column totals & 47 & 151 & 366 & 564 \\
& $(8.3 \%)$ & $(26.8 \%)$ & $(64.9 \%)$ & $(100 \%)$ \\
\hline
\end{tabular}

FIGURE 3

Chi-square Test for Signed versus Unsigned Reviews toward Evaluation Slant of Unfavorable, Neutral, and Favorable Reviews

allow more freedom to write a critical or negative review.

The same test was used to see if the affiliation of the reviewer was significantly related to the treatment (descriptive or analytical) given to the review. However, the number of observations for three categories-consultants, affiliates of research agencies, and free-lance writerswas too small to meet one of the chisquare test assumptions and had to be combined. Figure 4 shows the results of this test. The chi-square value was 41.17 with 3 degrees of freedom, which is significant at the criterion of .05. In other words, significant differences did occur in the types of reviews, among different catego- ries of reviewers. The proportions for different categories of reviews indicated a consistent pattern except in the "librarians" category. Other categories had proportions of analytical reviews in the range of $85.7 \%-90.3 \%$, while the same proportion was only $25 \%$ for librarians. It could be reasonably assumed that the significance of differences in the chi-square test was attributable to one category of librarians. This assumption was tested by excluding librarians from the chi-square matrix in another test. The results (chi-square value of 1.69 for 2 degrees of freedom) confirmed that no significant differences occurred among the three categories. Thus the only significance might be re-

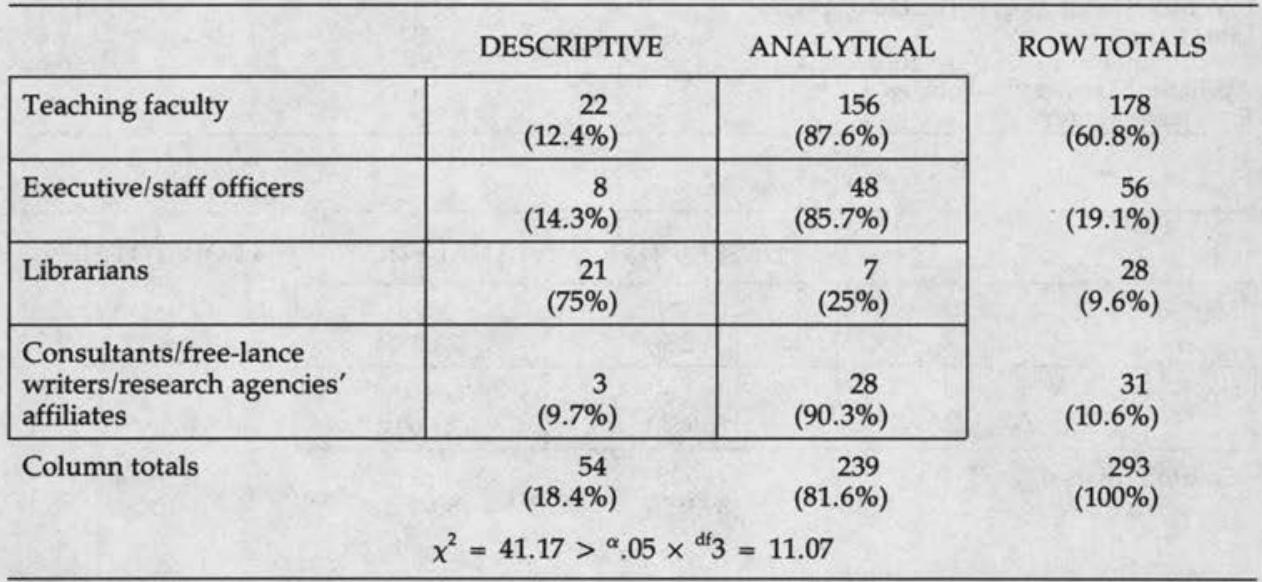

FIGURE 4

Chi-square Test for Reviewer Affiliations toward Descriptive versus Analytical Nature of Reviews 
lated to the category of librarians whose reviews were predominantly descriptive.

When the categorical data for reviewer affiliations were placed in a matrix of unfavorable, neutral, and favorable reviews, as shown in figure 5 , the chi-square was 17.5 with 10 degrees of freedom. The observed level of significance was .063 , greater than the criterion, .05, meaning that there were no significant differences. Thus no significant relationship was proved between affiliation of reviewer and favorable or unfavorable reviews.

\section{CONCLUSIONS}

The sample of book trade and professional journals used in this study had contrasting characteristics that seem to reflect their efforts to satisfy the different needs of their clientele. Reviews in the trade journals are relatively current, brief, descriptive, and without information about the reviewers. They usually did not provide any in-depth content analysis nor did they include critical comments on the substance and treatment of the monographs. Most of the opinions were neutral or favorable.
However, a typical review in a professional journal was published at a later date, provided a detailed analysis, and was more likely to be critical and evaluative in its treatment.

It was also found that signed reviews were more often analytical than unsigned. It was an additional finding that unsigned reviews had a significantly higher proportion of favorable evaluations. However, a probable explanation is that most of the unsigned reviews appeared in trade journals, many of which function as alerting as well as evaluative sources.

Results of this investigation also suggest that trade and professional management journals have characteristic reviewing patterns that meet the differing needs of, first, selectors and, second, scholars or practitioners.

Additional studies could be done to see if the profile established for management journal reviews (signed, longer, and more analytical than trade journals) holds true for other disciplines as well. Who reads the reviews in the professional journals and how they use the information would be another interesting topic. To what ex-

\section{UNFAVORABLE NEUTRAL FAVORABLE ROW TOTALS}

\begin{tabular}{|c|c|c|c|c|}
\hline Teaching faculty & $\begin{array}{r}20 \\
(11.2 \%)\end{array}$ & $\begin{array}{c}33 \\
(18.5 \%)\end{array}$ & $\begin{array}{c}125 \\
(70.2 \%)\end{array}$ & $\begin{array}{c}178 \\
(60.8 \%)\end{array}$ \\
\hline $\begin{array}{l}\text { Executives/ } \\
\text { staff officers }\end{array}$ & $\begin{array}{c}3 \\
(5.4 \%)\end{array}$ & $\begin{array}{c}9 \\
(16.1 \%)\end{array}$ & $\begin{array}{c}44 \\
(78.6 \%)\end{array}$ & $\begin{array}{r}56 \\
(19.1 \%)\end{array}$ \\
\hline $\begin{array}{l}\text { Consultants } \\
\text { industrial psychologists }\end{array}$ & $\begin{array}{c}7 \\
(35.0 \%)\end{array}$ & $\begin{array}{c}2 \\
(10 \%)\end{array}$ & $\begin{array}{c}11 \\
(55 \%)\end{array}$ & $\begin{array}{c}20 \\
(6.8 \%)\end{array}$ \\
\hline Librarians & $\begin{array}{c}3 \\
(10.7 \%)\end{array}$ & $\begin{array}{r}4 \\
(14.3 \%)\end{array}$ & $\begin{array}{c}21 \\
(75 \%)\end{array}$ & $\begin{array}{c}28 \\
(9.6 \%)\end{array}$ \\
\hline Free-lance writers & $\begin{array}{c}1 \\
(20 \%)\end{array}$ & $\begin{array}{c}2 \\
(40 \%)\end{array}$ & $\begin{array}{c}2 \\
(40 \%)\end{array}$ & $\begin{array}{c}5 \\
(1.7 \%)\end{array}$ \\
\hline $\begin{array}{l}\text { Research agencies' } \\
\text { affiliates }\end{array}$ & $\begin{array}{c}0 \\
(0 \%)\end{array}$ & $\begin{array}{c}2 \\
(33.3 \%)\end{array}$ & $\begin{array}{r}4 \\
(66.7 \%)\end{array}$ & $\begin{array}{c}6 \\
(2 \%)\end{array}$ \\
\hline \multirow[t]{2}{*}{ Column totals } & $\begin{array}{c}34 \\
(11.6 \%)\end{array}$ & $\begin{array}{r}52 \\
(17.7 \%)\end{array}$ & $\begin{array}{c}207 \\
(70.6 \%)\end{array}$ & $\begin{array}{c}293 \\
(100 \%)\end{array}$ \\
\hline & \multicolumn{3}{|c|}{$\chi^{2}=17.5<{ }^{\alpha} .05 \times{ }^{\mathrm{df}} 10=18.31$} & \\
\hline
\end{tabular}




\section{September 1987}

tent are readers' needs actually met? More investigations of the screening policies of journal editors in different disciplines would add significantly to our knowledge in this area, as would studies of publishers in a field. Which ones succeed in having the greatest number of their books reviewed? Much important information on reviews and reviewing awaits interested, eager investigators.

\section{REFERENCES}

1. John P. Schmitt and Stewart Saunders, "An Assessment of Choice as a Tool for Selection," College \& Research Libraries 44:357-80 (Sept. 1983).

2. Daniel Ream, "An Evaluation of Four Book Review Journals," $R Q$ 19:149-53 (Winter 1979).

3. Susan Fisher, "Book Reviews in Five Library Journals: A Comparative Analysis," Australian Library Journal 30:87-96 (Aug. 1981).

4. Beth McLeod, "Library Journal and Choice: A Review of Reviews," Journal of Academic Librarianship 7:23-28 (Mar. 1981).

5. Ching-Chih Chen and Arthuree M. Wright, "Current Status of Biomedical Book Reviewing: Part I. Key Biomedical Reviewing Journals with Quantitative Significance," Bulletin of Medical Library Association 62:105-12 (Apr. 1974).

6. Ching-Chih Chen, "Current Status of Biomedical Book Reviewing: Part II. Time Lag in Biomedical Book Reviewing," Bulletin of Medical Library Association 62:113-19 (Apr. 1974).

7. Ching-Chih Chen, "Current Status of Biomedical Book Reviewing: Part III. Duplication Patterns in Biomedical Book Reviewing," Bulletin of Medical Library Association 62:296-301 (July 1974).

8. Ching-Chih Chen, "Current Status of Biomedical Book Reviewing: Part IV. Major American and British Biomedical Publishers," Bulletin of Medical Library Association 62:302-8 (July 1974).

9. Ching-Chih Chen and Thomas J. Galvin, "Reviewing the Literature of Librarianship: A State of the Art Report," in American Reference Books Annual 1975 (Littleton, Colo.: Libraries Unlimited, 1974), p.xxxi-xlv.

10. John Budd, "Book Reviewing Practices of Journals in the Humanities," Scholarly Publishing 13:363-71 (July 1982).

11. Arthur P. Young, "Scholarly Book Reviewing in America," Libri 25:174-82 (Sept. 1975).

12. Trisha Gorman, "Which Books Should Get a Review? How Ten Magazines Choose," Publishers Weekly 220:23 (Nov. 6, 1981).

13. Marcy Murphy and Sajjad ur Rehman, "The Reviewing of Management Literature," Library Quarterly 57:32-60 (Jan. 1987).

14. American Book Publishing Record (New York: Bowker, 1981).

15. Business Periodicals Index (New York: Wilson, 1980-81, 1981-82, 1982-83, 1983-84).

16. Book Review Index (Detroit: Gale, 1980-83).

17. Ching-Chih Chen, "Current Status of Biomedical Reviewing: Part III," p.113-19.

18. Victoria Hargrave, "A Comparison of Reviews of Books in the Social Sciences in General and in Scholarly Periodicals," Library Quarterly 18:216-17 (July 1948).

19. Alma A. Covey, Reviewing of Reference Books: An Evaluation of the Effectiveness of Selected Announcement, Review and Index Media in Their Coverage of Reference Books (Metuchen, N.J.: Scarecrow, 1972), p.119.

20. Chen and Galvin, p.xxxviii.

21. Ibid.

22. McLeod, p.24. 